\title{
Computational Study of the Pyrolysis Reactions and Coke Deposition in Industrial Naphtha Cracking
}

\author{
Aligholi Niaei ${ }^{1}$, Jafar Towfighi ${ }^{2}$, Mojtaba Sadrameli ${ }^{3}$, Mir Esmaeil Masoumi ${ }^{4}$ \\ 1niaei@yahoo.com \\ 2 towfighi@modares.ac.ir \\ ${ }^{3}$ sadramel@modares.ac.ir \\ ${ }^{4}$ mmasoumi @modares.ac.ir
}

Chem. Eng. Dep., Tarbiat Modares University, P.O.Box 14155-4838, Tehran, Iran http//www.modares.ac.ir

\begin{abstract}
The aim of this study is to develop a mechanistic reaction model for the pyrolysis of naphtha that can be used to predict the yields of the major products from a given naphtha sample with commercial indices. For this purpose, a computer control pilot plant system designed and assembled by Olefin Research Group, for studying the pyrolysis reaction kinetics, coke formation and different advance control algorithms. Experiments on the thermal cracking of naphtha were carried out in a tubular reactor under conditions as close as possible to those in the industrial operations. The reaction mechanism of thermal cracking of hydrocarbons is generally accepted as free-radical chain reactions. A complete reaction network, using a rigorous kinetic model, for the decomposition of the naphtha feed has been developed, which is used for the simulation of industrial naphtha crackers. Simultaneous simulation of the reactor and the firebox, provides a detailed understanding of the behavior and an accurate prediction of the furnace run length.
\end{abstract}

\section{Introduction}

Thermal cracking of hydrocarbons is one of the main processes for the production of olefins. The feed, ranging from light gaseous hydrocarbons to gas oil, is cracked in 48 tubular coils suspended in a fired rectangular furnace. The heat required for the endothermic reactions is provided via radiation burners in the sidewall or long flame burners in the bottom of the furnace. Mathematical models describing the simulation of the pyrolysis reactors need to be combined with complex kinetic models with important features such as coking, heat and mass transfer, firebox profiles and fluid dynamic characteristics. The central part of the model is the kinetic mechanism and related constants. Typically, the chemistry component can consist of several hundred reactions involving large numbers of species, and this together with the coupling of the kinetic rate equations to the physical features can lead to computationally calculations. The use of full kinetic mechanisms for on-line simulations such as plant optimization is therefore rarely possible in order to obtain a favorable product 
distribution or to reduce unwanted side effects. The present paper describes the development of a kinetic reaction network for the pyrolysis of naphtha, and with the help of an accurate coking kinetic model, the calculation of the temperature and product distribution in the reactor length and run time can be achieved. Simultaneous simulation of the reactor and the firebox provides a detailed understanding of the behavior of the cracking furnace. The experimental pilot results and simulation for the naphtha cracking are in good agreement with the industrial data.

\section{Experimental Study}

The aim of this study is to develop a mechanistic reaction model for the pyrolysis of naphtha that can be used to predict the yields of major products from a given naphtha sample with commercial indices. With the aid of the previous research works[1-5], pyrolysis theories, experimental data and plant output data a complete pyrolysis reaction network is generated according to the major feed component of naphtha. For this purpose experimental data from thermal cracking pilot plant system and ARPC olefin plant data is used for developing reaction model. This paper describes a computer control pilot plant system which is designed and assembled by the Olefin Research Group(ORL), for studying of the pyrolysis reaction kinetics, coke formation and different advance control algorithms. The feedstock was straight run naphtha from ARPC with the composition presented in Table 1. The standard reaction condition ( $\mathrm{T}=810-860 \mathrm{C}$; residence time, $0.3-0.4 \mathrm{sec}$; total pressure $1 \mathrm{bar}$; dilution ratioH $\mathrm{H}_{2} \mathrm{O}$ /naphtha, 0.6- 0.8) are similar to those in the industrial reactors.

Table 1. Specification of Naphtha Feed (\%wt)

\begin{tabular}{|c|c|c|c|c|}
\hline Carbon No. & n-Paraffins & iso-Paraffins & Naphthenes & Aromatics \\
\hline 4 & 0.22 & 2.64 & & \\
5 & 25.22 & 17.94 & & \\
6 & 14.88 & 22.26 & 5.92 & 2.0 \\
7 & 1.67 & 4.42 & 1.09 & 0.67 \\
8 & & 0.57 & & 0.5 \\
\hline
\end{tabular}

\subsection{Experimental Setup and Procedure}

The setup, used for the experiments of the naphtha thermal cracking is a computer controlled pilot plant unit, shown schematically in Figure 1. The unit is consisted to three sections:

Operating Section. The operating section includes the feeding, preheating, reaction and quench parts. Both gaseous and liquid hydrocarbons can be fed. The hydrocarbon and diluent water are pumped into the preheaters. Gas flows are metered by means of mass flow controllers. Liquid hydrocarbons and water as dilution steam are fed by 


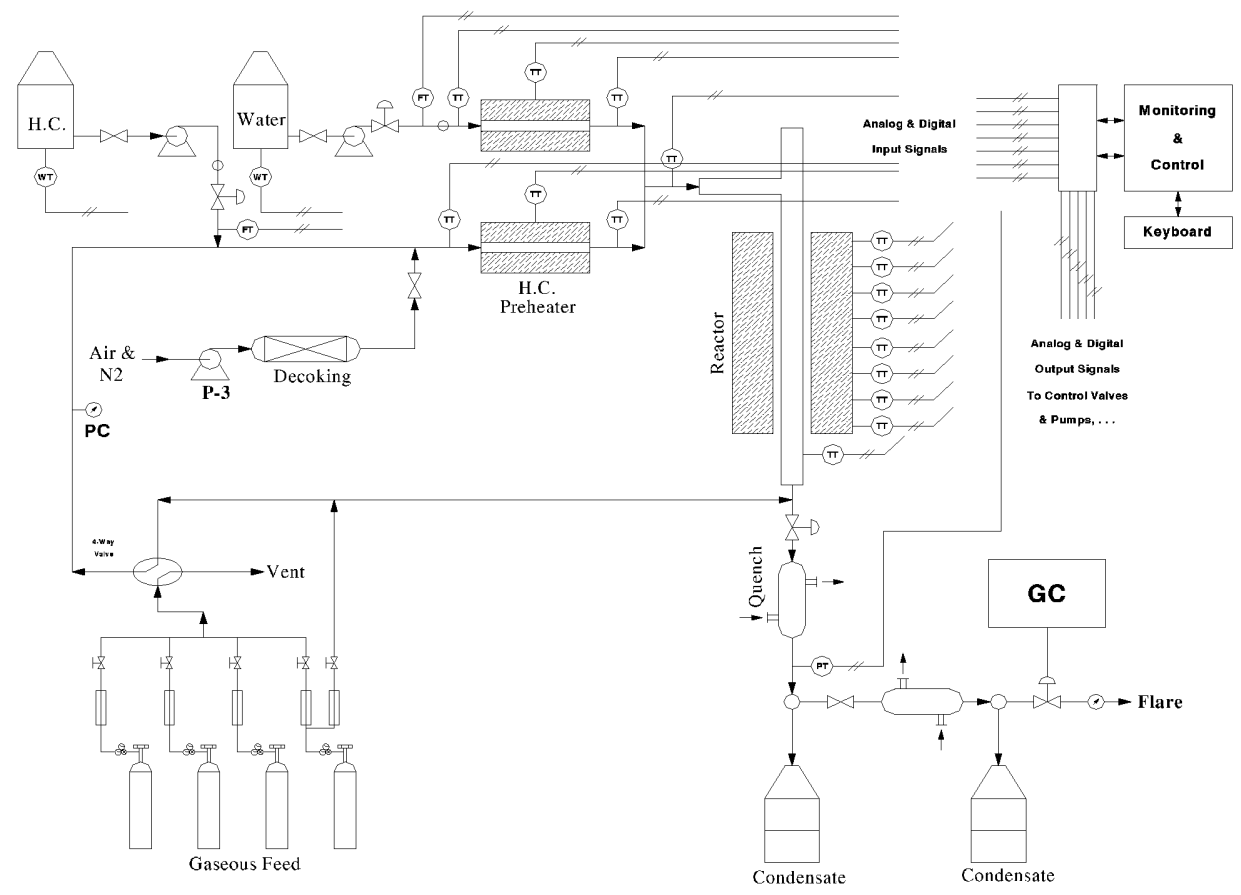

Fig.1. Flow Diagram of Thermal Cracking Pilot Plant

means of dowsing and pulsation-free pumps. The vessels containing the liquid feedstock are placed on digital balances witch is connected to the on-line computer for the feed monitoring. The setpoint of the pumps are set manually. The hydrocarbon and steam are perheated up $600^{\circ} \mathrm{C}$, and mixed.

The furnace is consisted of two electrical preheaters for the water and hydrocarbon feeds. An additional electrical heater is used for the reactor section. The preheaters are single zones and the reaction section heater is divided into eight zones, which can be heated independently to set any type of temperature profile. Each zone power can be controlled manually or by a control algorithm implemented on the process computer. The reactor is a $1000 \mathrm{~mm}$ long, $10 \mathrm{~mm}$ internal diameter tube, made of Inconel 600. There are eighteen thermocouples along the reactor, 8 inside the furnace, 8 on the external tube skin and additional 2 for measuring of XOT(Cross over temperature) and COT(Coil outlet temperature). The reactor is heated electrically and placed vertically in a cylindrical furnace. The pressure in the reactor is controlled by a back pressure from the reactor outlet. The analog signals of the thermocouples are connected to the process computer. The temperature reading is also visualized on a color digital thermometer display.

The reactor effluent is cooled in a double pipe heat exchanger by circulating ice water. Liquid products, tars and any possible solid particles cooled and separated by means of three glass condensers and cyclones. The cyclone is followed by a condenser in which steam and heavy products are condensed. The condensers is kept in a circulating ice water bath to maintain a constant temperature. A fraction of the product gas is then withdrawn for the on-line analysis on gas chromatograph, while the rest is sent directly to the flare. 
Analysis Section. The on-line analysis of the reactor effluent is performed by means of two computerized gas chromatographs. First a Varian Chrompack CP3800 with two flame ionization detector (FID), analyses the light components including hydrogen, methane, oxygen, carbon monoxide, carbon dioxide, light hydrocarbons up to $\mathbf{C} 4$, and internal standard nitrogen.

The second Varian Chrompack CP3800 with two detectors, a thermal conductivity detectors (TCD), analyses the light components including hydrogen and one flame ionization detector (FID) for the analysis of heavy components (PIONA) including $\mathrm{C} 5+$ and aromatics. The conditions of the GC systems were carried out under the conditions given in Table 2.

Table 2. Specification of Analysis System

\begin{tabular}{|l|c|c|c|}
\hline \multicolumn{4}{|c|}{ 1.Varian Chrompack CP3800 } \\
\hline & & Detector & Product analysis \\
\hline Column A & $\begin{array}{c}\text { Capillary } \\
\text { CP-CIL 5CB }\end{array}$ & FID & $\mathrm{C}_{2} \mathrm{H}_{4}, \mathrm{C}_{3} \mathrm{H}_{6}, \mathrm{C}_{4} \mathrm{H}_{6}$ \\
\hline Column B & Packed column & $\begin{array}{c}\text { Methanizer and FID } \\
\text { in series }\end{array}$ & $\mathrm{CO}, \mathrm{CO}_{2}$ \\
\hline \multicolumn{4}{|c|}{ 2.Varian Chrompack CP3800 } \\
\hline Column A & $\begin{array}{c}\text { Capillary CP - } \\
\text { CIL-PONA }\end{array}$ & $\begin{array}{c}\text { FID With } \\
\text { split/splittless }\end{array}$ & $\mathrm{C}_{5}+$, Aromatics \\
\hline Column B & Packed column & TCD & $\mathrm{H}_{2}, \mathrm{CH}_{4}$ \\
\hline
\end{tabular}

Computer Control Section. Computer control system consisted of hardware and software sections.

Hardware. The PIII process computer is connected on-line to the pilot plant and controls the main part of the unit. The connection with the pilot plant is done through analog to digital (A/D) converters, digital to analog (D/A) converters, and digital input-outputs.

Two Axiom A/D converters are available, one with 16-channel analog multiplexer for gas chromatographic signals and other a 32-channel analog multiplexer for the thermocouple signals. Ten D/A converters are available: two in AX-5411 system which provides the set points for water and hydrocarbon preheaters and eight in AX5212 system which provides the set points for 8 zones of reaction section heater. An electronically kit which was made in ORL, is used for sending the control signals to the final control element of heaters (Tiristors).

Thirty tow digital input-output are available, eight in AX-5232 system which was not used, and twenty four in Ax-5411 system which has connected to a AX-755 system and used as input switches to start and stop of dowsing and cooling water pumps and main power of the electrical heaters. Two serial ports (RS-232) from the computer main board is used for the signal processing of digital balances.

Software. The on-line computer control software can be divided into two main parts of monitoring and control. In monitoring section, the process gas, tubeskin and 
heaters wall temperatures are displayed on a screen by means of a visual $\mathrm{C}$ program in 32-bit window operating system. This software was developed in ORL of T.M.U. Water and hydrocarbon flow rates are calculated from the weight change on the digital balances and the sampling rate. Monitoring of digital balances are achieved by means of a visual basic program which was developed by AND company. In control part the temperature profile of the reactor is stabilized by temperature controlling in each zone by means of a conventional PID controller. The set points for this temperature stabilizing control are included in the software. Implementation of advanced controllers and time varying set points are possible. Performances of advanced controllers can be tested experimentally by the control software in the pilot plant. All pilot plant measurements and control system information are saved in the text and graphical mode.

\section{Kinetic Model Development}

Many efforts have been done for the development of the reaction networks of the thermal cracking. The simplest model contains 22 molecular reactions which is developed by Kumar and Kunzru [1]. A simulation program based on the fundamental free radical reaction kinetics was developed by Dente et al.[2,3]. Pyrolysis of naphtha and lumped component such as n-paraffin, isoparaffin, naphthene and aromatics in gross molecular reactions were investigated [4]. The aim of this study is to develop a complete mechanistic reaction network that can predict the behavior of the cracking coils in different operating conditions and major feed components of naphtha. A simulation program of the reaction kinetics inside the coils of a thermal cracking unit can provide information on the effects of changing feed properties or alternative operating conditions on the thermal cracking product distribution.

The reaction mechanism of the thermal cracking is generally accepted as freeradical chain reactions. A complete reaction network, using a rigorous kinetic model, for the decomposition of naphtha feed is developed, and is used for the simulation of a naphtha cracker. The detailed mechanistic kinetic scheme in this simulation network, developed, involves over 542 of reactions and 91 molecular and radical species. As usual this chain radical mechanism consists of several radical and molecular elementary reactions, which can be briefly summarized in Table 3 . On the basis of these intrinsic kinetic parameters, it was possible to describe the primary pyrolysis reactions of all the different hydrocarbon species and the generation of these reaction mechanisms allowed for development of the large kinetic schemes.

The governing mass, energy, and momentum balance equations for the cracking coil constitute the two-point boundary value problem which has a significant stiffness in the numerical simulation due to the large differences in concentration gradient between radicals and molecules. This problem can be tackled through the application of the Gear method. Details of the solution may be obtained from Towfighi et al. [5]. 
Table 3. Chemistry of the thermal cracking reactions

\begin{tabular}{|c|c|c|}
\hline Reactions & $\log (\mathrm{A})(1 / \mathrm{s}, 1 / \mathrm{mol} . \mathrm{s})$ & $\begin{array}{c}\mathrm{E} \\
(\mathrm{kcal} / \mathrm{mol})\end{array}$ \\
\hline \multicolumn{3}{|c|}{ Radical Reactions } \\
\hline \multicolumn{3}{|l|}{ Initiation } \\
\hline n- $\mathrm{C}_{6} \mathrm{H}_{14} \rightarrow \mathrm{C}_{2} \mathrm{H}_{5}+1-\mathrm{C}_{4} \mathrm{H}_{9}$ & 16.8 & 82 \\
\hline $\mathrm{C}_{3} \mathrm{H}_{8} \rightarrow \mathrm{H}^{\cdot}+1-\mathrm{C}_{3} \mathrm{H}_{7}$ & 17.3 & 92 \\
\hline \multicolumn{3}{|l|}{ H Abstraction } \\
\hline $\mathrm{H}^{\prime}+\mathrm{C}_{2} \mathrm{H}_{6} \rightarrow \mathrm{H}_{2}+\mathrm{C}_{2} \mathrm{H}_{5}$ & 11.1 & 9.7 \\
\hline $\mathrm{CH}_{3}+\mathrm{C}_{3} \mathrm{H}_{8} \rightarrow \mathrm{CH}_{4}+2 \mathrm{C}_{3} \mathrm{H}_{7}$ & 8.8 & 10.5 \\
\hline \multicolumn{3}{|l|}{ Radical Decomposition } \\
\hline $\mathrm{i}-\mathrm{C}_{4} \mathrm{H}_{9} \rightarrow \mathrm{CH}_{3}+\mathrm{C}_{3} \mathrm{H}_{6}$ & 14.2 & 32.7 \\
\hline $\mathrm{n}-\mathrm{C}_{4} \mathrm{H}_{9} \rightarrow \mathrm{H}+\mathrm{C}_{4} \mathrm{H}_{8}$ & 12.7 & 37.9 \\
\hline \multicolumn{3}{|l|}{ Radical Addition } \\
\hline $\mathrm{CH}_{3}{ }^{\circ}+\mathrm{C}_{3} \mathrm{H}_{6} \rightarrow 1, \mathrm{n}-\mathrm{C}_{4} \mathrm{H}_{9}{ }^{\circ}$ & 8.5 & 7.4 \\
\hline $\mathrm{CH}_{3}{ }^{\circ}+\mathrm{C}_{2} \mathrm{H}_{4} \rightarrow 1 \mathrm{C}_{3} \mathrm{H}_{7}$ & 8.1 & 7.7 \\
\hline \multicolumn{3}{|l|}{ Termination Reactions } \\
\hline $\mathrm{C}_{2} \mathrm{H}_{5}+\mathrm{C}_{2} \mathrm{H}_{5} \rightarrow \mathrm{n}-\mathrm{C}_{4} \mathrm{H}_{10}$ & 12.3 & 0.0 \\
\hline $\mathrm{CH}_{3}+\alpha-\mathrm{C}_{3} \mathrm{H}_{5}{ }^{\circ} \rightarrow 1-\mathrm{C}_{4} \mathrm{H}_{8}$ & 12.9 & 0.0 \\
\hline \multicolumn{3}{|c|}{ Molecular Reactions } \\
\hline \multicolumn{3}{|l|}{ Olefin Isomerization } \\
\hline $1-\mathrm{C}_{4} \mathrm{H}_{8} \rightarrow 2-\mathrm{C}_{4} \mathrm{H}_{8}$ & 12.4 & 14.3 \\
\hline $2-\mathrm{C}_{4} \mathrm{H}_{8} \rightarrow 1-\mathrm{C}_{4} \mathrm{H}_{8}$ & 12.3 & 14.8 \\
\hline \multicolumn{3}{|l|}{ Olefin Decomposition } \\
\hline $1,3-\mathrm{C}_{4} \mathrm{H}_{6}+\mathrm{C}_{2} \mathrm{H}_{2} \rightarrow \mathrm{C}_{6} \mathrm{H}_{6}+\mathrm{H}_{2}$ & 11.2 & 5.38 \\
\hline $1,3-\mathrm{C}_{4} \mathrm{H}_{6}+\mathrm{C}_{2} \mathrm{H}_{4} \rightarrow$ Cyclo $\mathrm{C}_{6} \mathrm{H}_{10}$ & 10.5 & 6.33 \\
\hline
\end{tabular}

\section{Coking Model}

Coke formation in the pyrolysis of hydrocarbons is a complex phenomena due to the various free radical reactions involved. Three mechanisms contribute to the deposition of a coke layer include catalytic coking, asymptotic coking and condensation of polyaromatic. Asymptotic coking is the main mechanism occurs from the interaction between active sites on the coke layer with gas phase coke precursors. At the free radical sites unsaturated precursors from the gas phase react via addition, followed by a set of dehydrogenation and cyclization reactions finally yielding a graphitic coke layer. The present paper attends on the asymptotic coking mechanism and describes the development of a kinetic coking model in the pyrolysis of naphtha. A number of coke precursors are found to be contributed to the formation of coke. Literature survey and experimental data led to a coking model in which a number of coke precursors and the relative rates of coke deposition contribute to the formation of coke. The precursors are classified into different groups such as Olefinic (ethylene, propylene, 1-butene, 2-butene), Dienes(propadiene, butadiene), Acetylenic, 
Aromatics(benzene, toluene, xylene, styrene ), Naphthenes and $\mathrm{C}_{5}+$ (unsaturate). The rate of coke formation out of olefinic group may be expressed as:

$$
r_{\text {colefinic }}=\left(\alpha \cdot C_{C 2 H_{4}}+\beta \cdot C_{C 3 H 6}+\gamma \cdot C_{C 4 H_{8}}\right) k_{0} \cdot e^{-E / R T}
$$

A reference component is chosen in each group (e.g. $\mathrm{C}_{2} \mathrm{H}_{4}$ in olefinic group) and $\alpha$, $\beta, \gamma$ the factors obtained from the relative coking rate derived by Kopinke et al.[6-8]. A similar approach lead to the coking model for the other groups is considered and 6 parallel reactions are achieved. The total rate of coke formation is expressed as:

$$
r_{c}=\sum_{i=1}^{6} r_{c, \text { Group }}
$$

Since the coking is slow, quasi steady state conditions may be assumed, so that, the deposition of coke can be shown as:

$$
\frac{\partial C}{\partial t}=\left(d_{t}-2 t_{c}\right) \frac{\alpha . r_{c}}{4 \rho_{c}}
$$

Using the mathematical model, the amount of coke deposited on the internal wall of the reactor tubes has been calculated with a limiting value for tube skin temperature (e.g. for sample olefin plant is $1100^{\circ} \mathrm{C}$ ). In the following, the effect of the coke thickness on the operating parameters has been demonstrated in the onstream time of the furnace.

\section{Results and Discussion}

The results of simulation in a sample industrial naphtha cracking furnace are illustrated in Figures 2-5. Table 4 shows the characteristics of a naphtha cracking furnace is used in present simulation. Figure 2 presents the variation of main products in the length of the reactor. Figure 3 shows the main products yield such as ethylene, propylene, butadiene and aromatic over the run time of the reactor. The feed flow rates were also kept constant over the run length. The growth of the coke layer and the amount of heat transferred to the reacting process gas and pressure level are factors, which affect the ethylene yield and selectivity.

Figure 4 shows the simulated coke layer thickness as a function of run length. The coke formation takes place at the temperature of the gas/coke interface. As a consequence, the coke layer grows fast there and creates an additional resistance to the heat transfer and causes a decrease of the tube cross sectional area. Increasing the heat fluxes increases the gas/ coke interface temperatures and the coking rates. The coke deposition reaches its maximum thickness in the last pass at the length of $42 \mathrm{~m}$.

Figure 5 shows the evolution of the simulated process gas, coke surface, inner tube wall and external wall temperatures of coil in the length of reactor. In the first part of the reactor, the temperature profile shows a significant increase as well, but this is 
Table 4. Basic Information of Industrial Cracking Furnace

\begin{tabular}{|l|l|}
\hline \multicolumn{1}{|c|}{ Furnace characteristics } & \\
Height $(\mathrm{m})$ & 11.473 \\
Length $(\mathrm{m})$ & 10.488 \\
Depth $(\mathrm{m})$ & 2.1 \\
No. of side wall burners & 108 \\
$\quad$ Reactor configuration & \\
Total length $(\mathrm{m})$ & 45 \\
Total length pass 1: $(\mathrm{m})$ & 22.5 \\
Internal / External dia.(mm) & $85 / 92$ \\
Total length pass $2:(\mathrm{m})$ & 22.5 \\
Internal / External dia.(mm) & $121 / 130$ \\
& $-1.257+0.0432 \mathrm{~T}$ \\
$\quad$ Material properties & 6.46 \\
Tube thermal conductivity & 1680 \\
Coke thermal conductivity & \\
Coke specific gravity $\left(\mathrm{kg} / \mathrm{m}^{3}\right)$ & \\
\hline
\end{tabular}

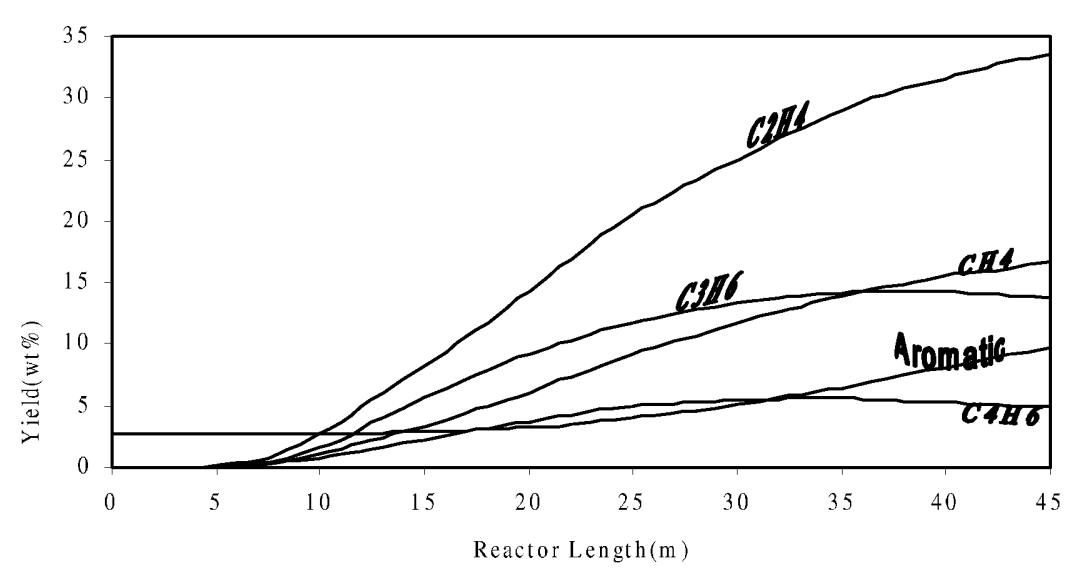

Fig. 2. Protile of main Product Y1elds along the Coil at End of Run of the Furnace

mainly due to the higher heat flux. The peaks in the external tube skin temperature profile correspond to the higher temperature in the bottom of the furnace. The maximum value is reached at the end of second part. The on-stream time of cracking furnace is limited by the external tube skin temperature. In present investigation the maximum allowable temperature at the second part of coil is 1100 reached after 75 days. The simulated value is in agreement with the industrial plant data. The tube skin temperatures that are measured by the pyrometer, other thermal characteristics of the furnace such as gas and refractory temperatures and heat flux measurement are impossible or inaccurate. 


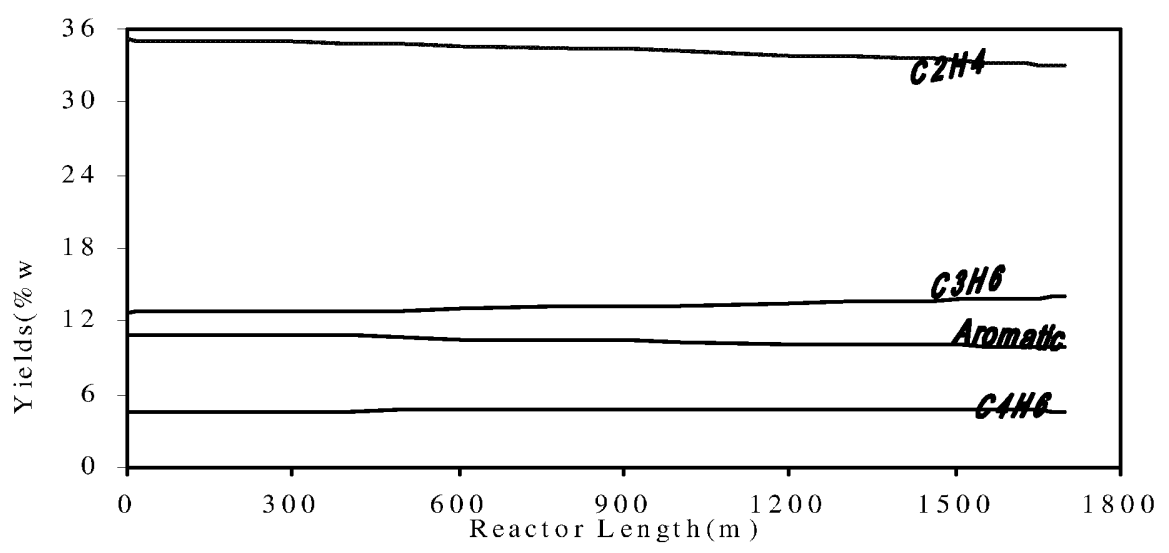

Fig. 3. Profile of main Product Yields along Run Time of the Furnace

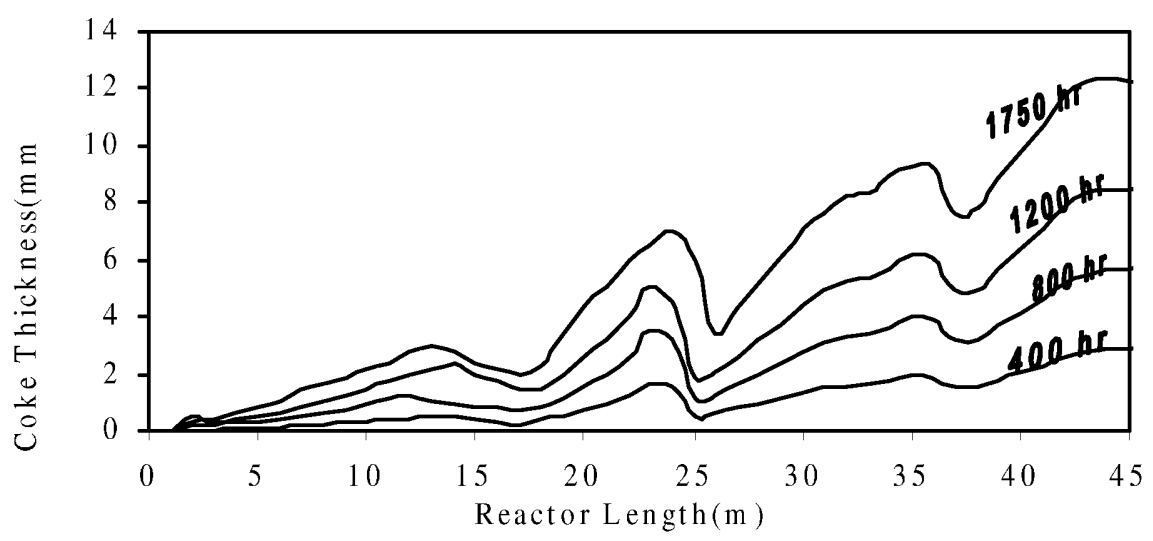

Fig. 4 Variation of Coke Thickness along the Coil at Different Run Length

\section{Conclusion}

Detailed and accurate information can be obtained from this simulation. The growth of a coke layer is accurately simulated, and so is the evolution of the external tube skin temperatures. The simulated and plant observation run lengths are in good agreement. Simulations of this kind can be used to optimize the furnace operation for the various feedstock and operating conditions. They can be used as a guide for the adaptation of the operating variables aiming at prolonging the run length of the furnace. The model and simulation software presented here are used as a guide for plant operation in olefin plant to control the furnace parameters. 


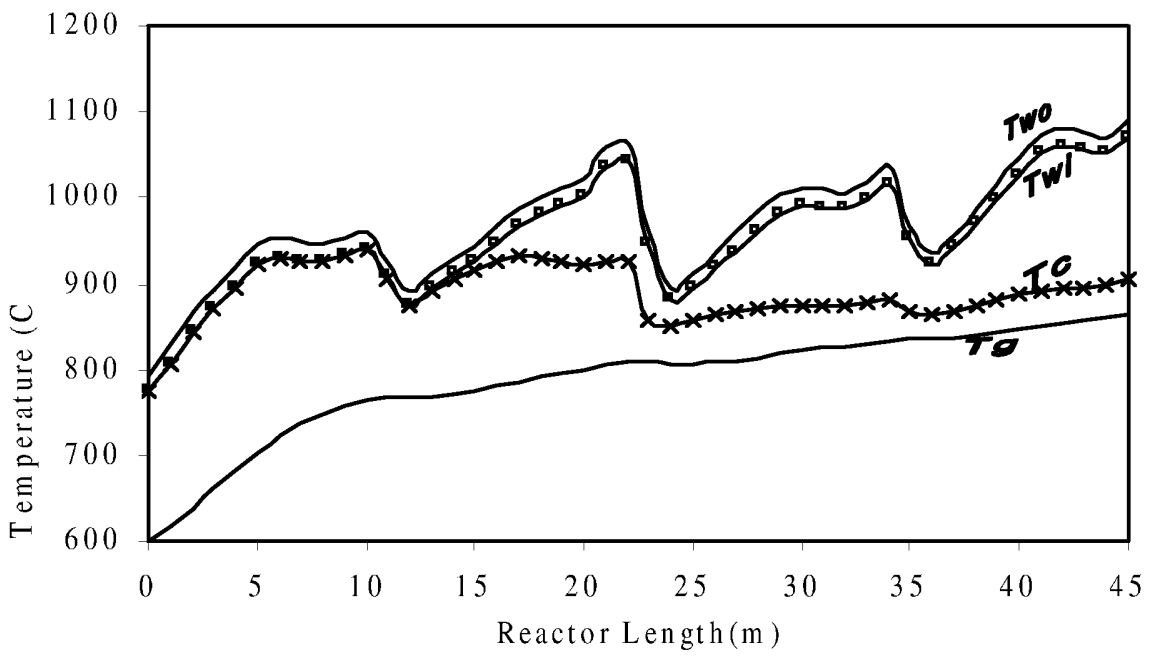

Fig. 5. Profile of process gas $\left(T_{g}\right)$, coke surface $\left(T_{c}\right)$, inner wall of coil $\left(T_{w i}\right)$ and external tube $\operatorname{skin}\left(\mathrm{T}_{\mathrm{wo}}\right)$ temperature along the cracking coil

Acknowledgment. The authors acknowledge the support given by olefin units of ARPC and TPC petrochemical companies of Iran.

\section{Nomenclature}

C Accumulation of coke (m)

$\mathrm{d}_{\mathrm{t}} \quad$ Tube diameter $(\mathrm{m})$

E Activation energy $(\mathrm{J} / \mathrm{mole})$

$\mathrm{r}_{\mathrm{c}} \quad$ Coking reaction rate $\left(\mathrm{kg} / \mathrm{m}^{3} . \mathrm{s}\right)$

$t_{c} \quad$ Coke thickness $(m)$

t Time ( hr)

$\mathrm{T} \quad$ Temperature $\left({ }^{\circ} \mathrm{K}\right)$

$\alpha \quad$ coking factor

$\rho_{\mathrm{c}} \quad$ coke density $\left(\mathrm{kg} / \mathrm{m}^{3}\right)$

\section{References}

1. Kumar, P. and Kunzru, D.: Ind.Eng. Chem.Proc. Des. Dev., 32 (1985) 774-782

2. Dente, M., Ranzi, E., Goossens, A. G.: Comput. Chem. Eng., 3 (1979) 61-72

3. Dente, M., Ranzi, E., Bozzano, G., Faravelli, T., Valkenburg, P.J.M.: AIChE Meeting, TX,75 (2001),1-20

4. Van Damme, P.S., and Froment, G.F.: Ind. Eng. Chem. Proc. Des. Dev., 20(1981) 366-376

5. Towfighi, J., Nazari, H. Karimzadeh, R.: APCCHE / CHEMECA 93, Melbourne, Australia, 3 (1993) 337-342

6. Kopinke, F.D., Zimmermann, G., Nowak, S.: Carbon, 56,2 (1988) 117-124

7. Kopinke, F.D., Zimmermann, G., Reyners, G., Froment, G.F.: Ind. Eng. Chem. Res., 32(1993a) 56-61

8. Kopinke, F. D., Zimmermann, G., Reyners, G., Froment, G.F.: Ind. Eng. Chem. Res., 32(1993b) 2620-2625 